\title{
Primary System Test Facility Review
}

\author{
Terry J. Morton
}

August 2019

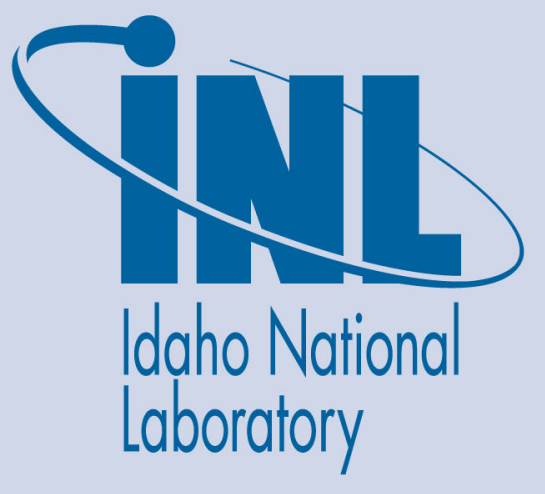

The INL is a U.S. Department of Energy National Laboratory operated by Battelle Energy Alliance 


\section{DISCLAIMER}

This information was prepared as an account of work sponsored by an agency of the U.S. Government. Neither the U.S. Government nor any agency thereof, nor any of their employees, makes any warranty, expressed or implied, or assumes any legal liability or responsibility for the accuracy, completeness, or usefulness, of any information, apparatus, product, or process disclosed, or represents that its use would not infringe privately owned rights. References herein to any specific commercial product, process, or service by trade name, trade mark, manufacturer, or otherwise, does not necessarily constitute or imply its endorsement, recommendation, or favoring by the U.S. Government or any agency thereof. The views and opinions of authors expressed herein do not necessarily state or reflect those of the U.S. Government or any agency thereof. 


\title{
Primary System Test Facility Review
}

\author{
Terry J. Morton
}

August 2019

Idaho National Laboratory Idaho Falls, Idaho 83415

http://www.inl.gov

\author{
Prepared for the \\ U.S. Department of Energy \\ Office of Nuclear Energy \\ Under DOE Idaho Operations Office \\ Contract DE-AC07-05ID14517
}




\section{CONTENTS}

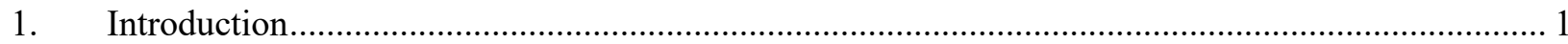

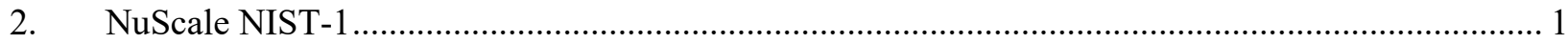

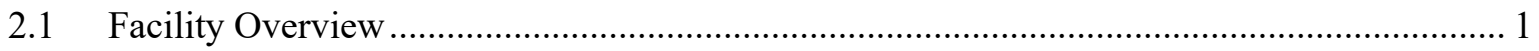

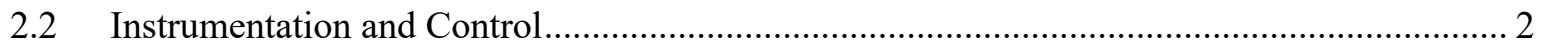

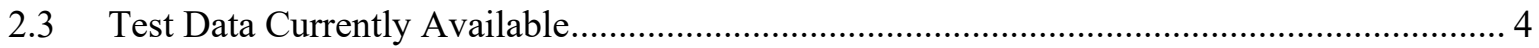

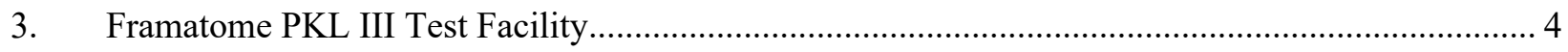

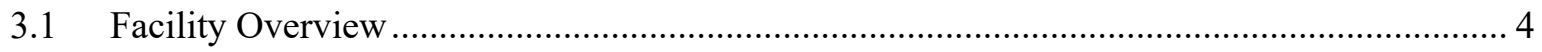

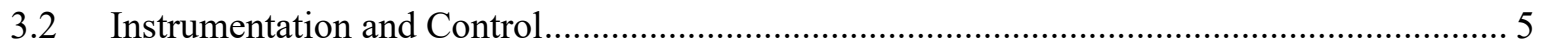

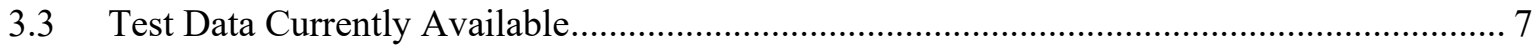

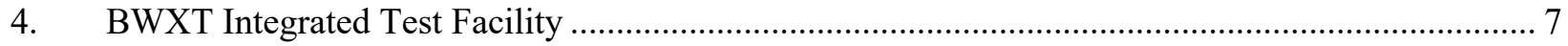

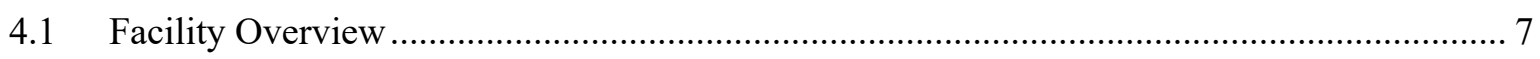

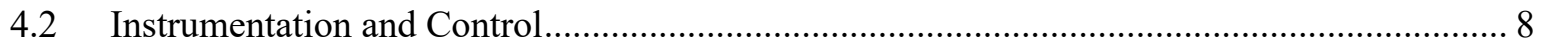

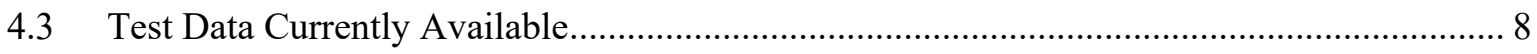

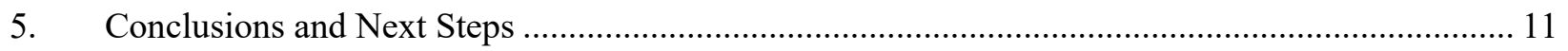

\section{FIGURES}

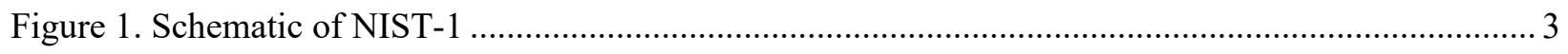

Figure 2. Cross-Sectional Representation of PKL III (One of Four Loops Shown) ................................... 6

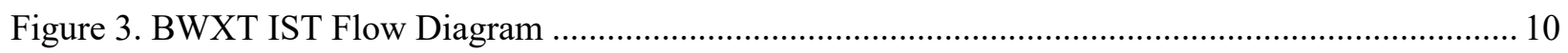




\section{Primary System Test Facility Review}

\section{Introduction}

Idaho National Laboratory (INL) is designing a Dynamic Energy Transport and Integration Laboratory (DETAIL) to demonstrate the operation of an integrated energy system as part of supporting research and development needs for the DOE Office of Nuclear Energy Integrated Energy Systems (IES) Program. DETAIL will demonstrate real-time integration with the electrical grid, renewable energy inputs, thermal and electrical energy storage, and energy delivery to an end user. A Thermal Energy Distribution System (TEDS) is being constructed within the DETAIL facility to demonstrate the operation of integrated energy system heat transfer components, thermal energy storage, distribution systems, and instrumentation and control (I\&C), which will allow the facility to emulate the distribution of thermal energy to the generation of electrical power, and/or producing non-electrical commodities (e.g., hydrogen). As is the case for other subsystems within DETAIL, TEDS is designed to operate either independently or as a part of an integrated system to demonstrate the operation of integrated components, develop and validate thermal energy transport models and control systems, and study thermal energy inertia and energy storage.

In an effort to completely understand how TEDS will integrate with operational plants, data from tests previously run at existing integral system test facilities (IST) will be used to drive the TEDS heater. Alternatively, a real-time data connection would allow steam conditions at the IST to drive the TEDS heater at the same time as having TEDS conditions provide feedback to the IST in terms of steam demand and/or pressure. This integrated testing approach will assess the ability of TEDS to operate during all plant conditions.

Three existing integral system test facilities have been reviewed to determine their suitability for demonstrating TEDS capabilities when integrated within the DETAIL. This report summarizes the capabilities of each IST facility and any challenges that must be overcome to meet the operational needs of TEDS and DETAIL.

\section{NuScale NIST-1}

\subsection{Facility Overview}

The NuScale Integral System Test (NIST-1) facility is a physically-scaled, electrically-heated, thermal-hydraulic emulation of the NuScale Power Module (NPM) used to assess NPM thermalhydraulic conditions during normal operations and passive safety system responses during transient operations. The data generated is used for verification and validation (V\&V) of NPMspecific thermal-hydraulic codes. The facility is located on the Oregon State University (OSU) campus in Eugene, OR and is leased from OSU and managed by NuScale Power, LLC.

The NPM is a light-water, small modular reactor (SMR) that integrates all components for steam generation and heat exchange into a single unit. The full NuScale plant design will consist of twelve NPM, which will be monitored and operated from one control room. The NPM is currently undergoing design certification (DC) with the Nuclear Regulatory Commission (NRC). It is anticipated that the first NuScale plant will be built under the Carbon Free Power Project (CFPP) by the Utah Associated Municipal Power Systems (UAMPS), with the plant sited at INL. One NPM within the CFPP is currently being planned to support research, development and 
demonstration (RD\&D) activities within the Joint Use Modular Plant (JUMP) program. A priority RD\&D activity within JUMP is the demonstration of integrated system operation that could include use of heat/steam from the JUMP NPM for hydrogen production.

NIST-1 emulates the NPM at a scale of 1:3.3 in length, 1:227.5 in volume, 1:227.5 in heat transfer surface area, 1:68.94 in loop cross-sectional flow area, and 1:1 in time. 56 electric resistance heaters, generating a total of $406 \mathrm{~kW}$, emulate decay heat in the NPM. These heaters are grouped into two banks, with each bank being controlled with a silicon-controlled rectifier (SCR) controller, which allows the operator to modulate heater output.

NIST-1 consists of a reactor pressure vessel (RPV), pressurizer (PZR), containment vessel (CNV), cooling pool vessel (CPV), feedwater system, main steam system, decay heat removal system (DHRS), chemical and volume control system (CVCS), emergency core cooling system (ECCS), and associated piping arranged to emulate the NPM and allow a range of transients to be analyzed. See Figure 1 for a rendering of NIST-1.

\subsection{Instrumentation and Control}

Sensors monitor temperature, static pressure, differential pressure, electric power, flow rate, stress/load, and heat flux at multiple points, with the associated data transmitted to a central controller. Data from these sensors are acquired by a National Instruments data acquisition and control system (DACS) with a LabView-based user interface. Sensor data is sampled and stored at a frequency of $2 \mathrm{~Hz}$, with that sampling rate being adjustable in the LabView software.

NIST-1 is not currently capable of real-time interface with external sources as the computers that control the facility are not connected to the internet. Once NuScale-specific testing at NIST1 is complete (estimated September 2020), the facility could be reconfigured to support a realtime connection with external sources via an internet connection to NIST-1's I\&C system and one of INL's digital real time simulators located in the INL Systems Integration Laboratory. 


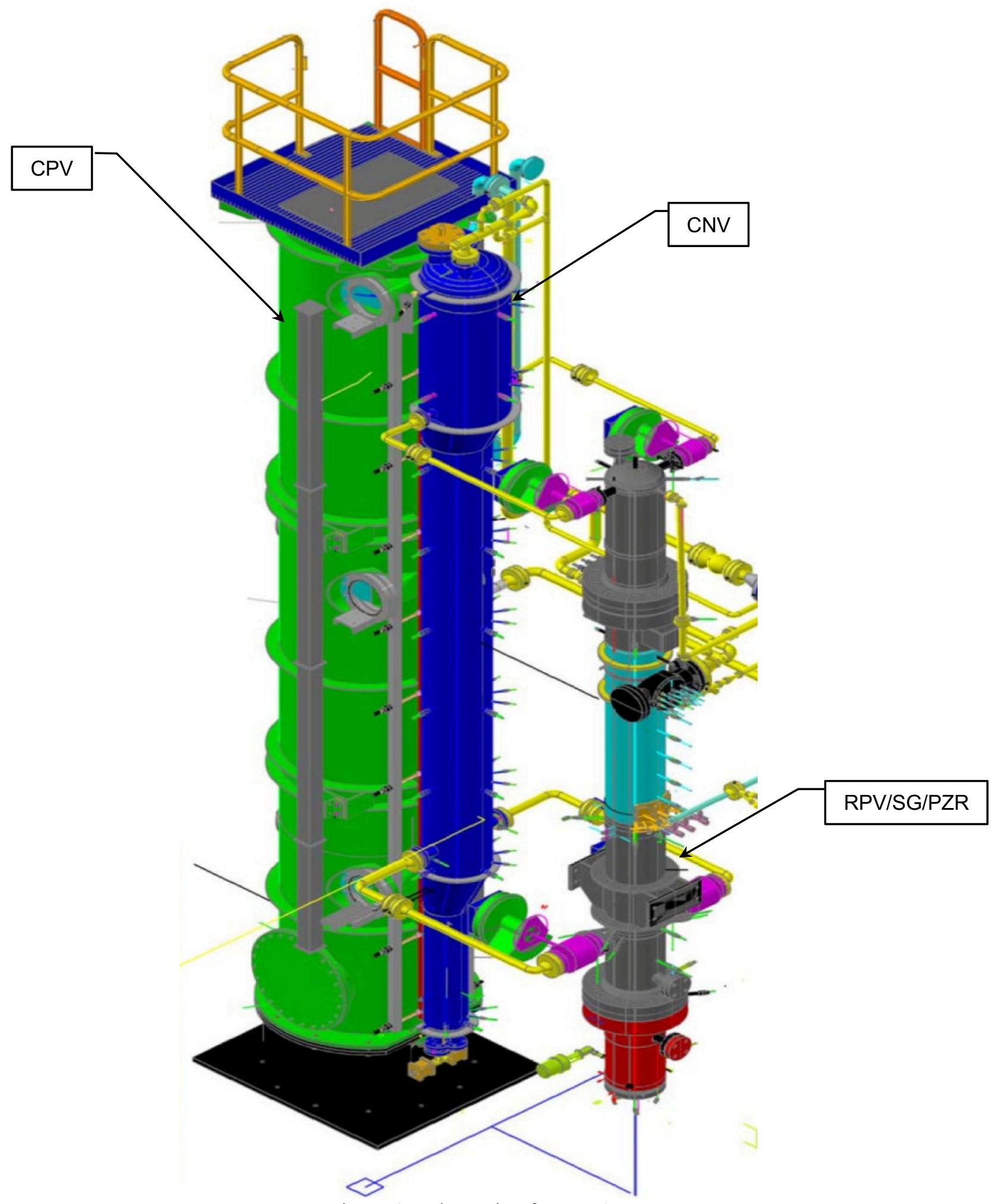

Figure 1. Schematic of NIST-1 


\subsection{Test Data Currently Available}

The following tests have been conducted at NIST-1 in support of the NPM design certification application (DCA) and to verify and validate the facility design and analysis models.

- Volume \& Elevation Test (as-built facility geometry characterization)

- Powered Natural Circulation Flow Loss (natural circulation flow and primary-tosecondary heat transfer characterization)

- $\quad$ ECCS Reactor Vent Valve (RVV) Spurious Opening

- Chemical and Volume Control System (CVCS) Discharge Pipe Break Inside CNV (loss of coolant accident (LOCA) without decay heat removal system (DHRS))

- PZR Spray Line Break (LOCA without DHRS)

- PZR Spray Line Break (large break LOCA without DHRS)

- High Pressure Condensation (CNV liquid level and heat transfer)

- Volume Drain Down Test (CPV Only)

- DHRS Full Length Characterization

- Cooling Pool Characterization

- Reactor Flow Stability (natural circulation flow stability following oscillations caused by step changes in core power and secondary side flow rate)

- Loss of Feedwater Flow (without DHRS)

- Loss of Feedwater Flow with DHRS Actuation

- Long-Term Cooling with Containment Initialized at Atmospheric Conditions (without DHRS)

- Long-Term Cooling with Containment Initialized at Vacuum Conditions (without DHRS)

- $\quad$ CVCS Discharge Pipe Break Rerun (LOCA without DHRS)

- Containment Vessel (CNV) Heat Loss Characterization

- RPV Heat Loss Characterization

- ECCS RVV Spurious Opening with 3 RVVs (without DHRS)

- $\quad$ CVCS Discharge Pipe Break with Single RVV Failure

- Loss of Feedwater Flow with DHRS

- Loss of Feedwater Flow with DHRS) Higher Decay Power

- Loss of Feedwater Flow with DHRS, Riser Uncovery

- $\quad$ ECCS Reactor Recirculation Valve (RRV) Spurious Opening (without DHRS)

Data from the transient analyses are proprietary and require some discussion with NuScale before they can be shared with INL. Specific transient data may be available upon request (see 2.2 for more information on the types of data available). The NIST-1 facility should be available to run JUMP-specific transients in the third and fourth quarters of calendar year 2020.

\section{Framatome PKL III Test Facility}

\subsection{Facility Overview}

The Framatome PKL III test facility is a physically-scaled, electrically-heated, thermal-hydraulic emulation of a four-loop, Westinghouse-style pressurized water reactor (PWR) used for accident analyses. The facility is located on the Siemens AG campus in Erlangen, Germany.

PKL III emulates Philippsburg Unit 2 (a German, pre-KONVOI (generation III) PWR located near Karlsruhe, Germany) at a scale of 1:1 in height, 1:12 in diameter, and 1:145 in volume. 
PKL III consists of four identical reactor coolant loops arranged symmetrically around an RPV. It includes all major primary and secondary operational and safety systems seen in a typical fourloop PWR. 314 electric resistance heaters, generating a total of $2.5 \mathrm{MW}$ (peak) or $1.7 \mathrm{MW}$ (continuous), emulate decay heat in the core. The heaters are grouped into three concentric zones with each zone having independent control allowing the operator to adapt the radial power profile. The facility design focuses on emulation of conditions that would follow an accident initiator and unplanned shutdown of the reactor. The heaters currently have no reactivity feedback programmed into their control and thus cannot emulate power operations of a nuclear power plant.

\subsection{Instrumentation and Control}

Sensors monitor temperature, static pressure, differential pressure, electric power, flow rate, stress/load, and heat flux at multiple points, with the associated data transmitted to a central controller. Data from these sensors are acquired by a National Instruments DACS with a LabVIEW-based user interface at a sampling rate that is adjustable in the LabView program.

The PKL III is capable of a real-time interface with TEDS allowing an integrated test with emulated steam demand and reactivity feedback. This interface would be via an internet connection to PKL-III's I\&C system and one of INL's digital real time simulators located in the INL Systems Integration Laboratory. 


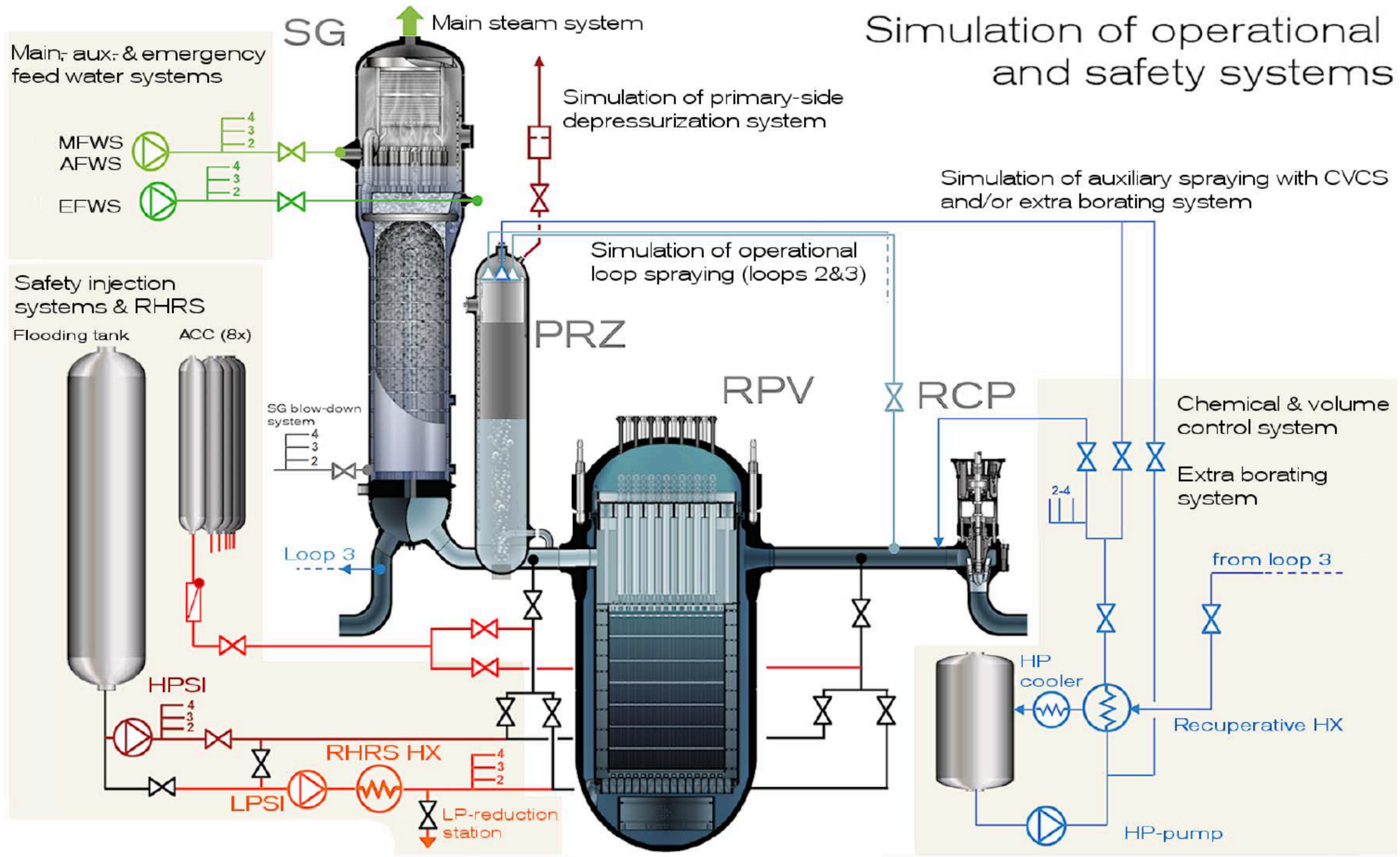

Figure 2. Cross-Sectional Representation of PKL III (One of Four Loops Shown) 


\subsection{Test Data Currently Available}

The PKL III facility has, by far, the most extensive set of transient analyses of the facilities evaluated due to the length of time it has been in operation (since 1986). In addition to design basis event analyses for licensing, the PKL III facility has been used to analyze normal and emergency operating procedures and their effects on the safe shutdown of a PWR.

- Loop Characterization Tests

- Shutdown with reactor coolant pumps (RCP) in Operation

- Loss of Off-Site Power (LOOP)

- Restart of RCPs with Large Steam Bubble in reactor pressure vessel (RPV) Head

- Small Break LOCA

- Loss of Feedwater

- Investigation of Accident Management Procedures (recovery from multiple accidents analyzed)

- Investigation of Beyond Design Basis Event Shutdown Procedures (multiple beyond design basis events analyzed)

- Investigation of Thermohydraulic Two-Phase Flow Phenomena

- Investigation of Thermohydraulic Behavior with Non-Condensible Gas in Primary Coolant

- Steam Line Break

- Primary Side Feed and Bleed Following Small Break LOCA

- Primary or Secondary Side Feed and Bleed Following steam generator tube rupture (SGTR)

- Investigation of Reflux Condensation Phenomena

- Secondary Side Feed and Bleed Following Loss of Feedwater (LOFW) or Station Blackout (SBO)

- $\quad$ Primary Side Feed and Bleed Following LOFW or SBO

- Small Break LOCA

- Cooldown Under Asymmetric Conditions (one or more steam generators isolated)

- Natural Circulation Under Small Break LOCA Conditions

- Recovery from Small Break LOCA with Failure of Safety Injection System

- Loss of Residual Heat Removal System During Mid-Loop Operation

- Optimization of Cooldown Procedure Following SGTR (1 tube)

- Analysis of System Behavior with Hydrogen in Primary System

This is not a comprehensive list of the transients run at PKL III, but it provides an overall idea of the types of transients that have been run. Data from these analyses could be available to INL with some export control restrictions. Real-time connection of PKL III to TEDS is possible but might require some programming changes on Framatome's side at additional costs to INL (cost estimate not yet developed). The PKL III is also available to run custom transients if necessary.

\section{BWXT Integrated Test Facility}

\subsection{Facility Overview}

The BWXT Integrated System Test (IST) facility is a physically-scaled, electrically-heated, thermal-hydraulic emulation of the mPower SMR used for transient analyses and thermal- 
hydraulic code V\&V. The facility is located at the Liberty University Center for Energy Research and Education (CERE) in Bedford County, Virginia.

The mPower SMR is a light-water SMR that integrates all components for steam generation and heat exchange into one vessel located in an underground containment. The mPower program was abandoned during NRC design certification, and the NRC review was suspended at that time.

The BWXT IST consists of an RPV, a once-through steam generator, a PZR, and associated piping. 1.25 MW of electric resistance heaters emulate decay heat and critical power heat in the core. The heaters are grouped into four, concentric banks of heaters, with each bank being individually controllable. See Figure 3 for a flow diagram of the facility showing major components of the facility.

The BWXT facility is currently shut down and would require INL investment to restore it to operation. The facility must be staffed by supervisory, operations, test, and engineering personnel, and this staff must be trained. The facility would then be re-commissioned to include valve lineups, instrument and DACS verification, and system startup.

\subsection{Instrumentation and Control}

Sensors monitor temperature, static pressure, differential pressure, electric power, flow rate, stress/load, and heat flux, at multiple points, with the associated data transmitted to a central controller. Heater power, variable pump speeds, and valve positions are controlled by the same central controller. Data from these sensors is acquired by a DeltaV DACS from Emerson. Data is stored as it comes from each sensor, i.e., sampling frequency is a function of the sensor type and manufacturer.

The BWXT IST is capable of a real-time interface with TEDS allowing an integrated test with emulated steam demand and reactivity feedback. This interface would be via an internet connection to BWXT IST's I\&C system and one of INL's digital real time simulators located in the INL Systems Integration Laboratory. Real-time connection would require some programming to interface the Emerson DeltaV software of the BWXT IST with the TEDS LabView software.

\subsection{Test Data Currently Available}

The following tests have been conducted at BWXT's IST prior to its shutdown to verify and validate the facility design and in support of the mPower DCA.

- Instrumentation Testing and Characterization

- Characterization of IST Simulated Core Heaters (various)

- Integral Economizer Once Through Steam Generator (IEOTSG) Performance Testing

- Nominal Conditions

- IEOTSG Performance Testing, Low Power

- IEOTSG Performance Testing, Reduced Feedwater Temperature

- IEOTSG Performance Testing, Increased Steam Pressure

- IEOTSG Performance Testing, Decreased Steam Pressure

- IEOTSG Performance Testing, Increased Feedwater Temperature

- IEOTSG Performance Testing, Constant Minimum Superheat 
○ IEOTSG Performance Testing, Constant Average Temperature

- PZR /IEOTSG Control Algorithms (various)

- IST Natural Circulation Testing

- Characterization

- Single Phase

- Two-Phase Cooling

- Boiler-Condenser Cooling

- RWST Cooling

- Reactivity Insertion Accident (by Program)

- Loss of Reactor Coolant Pumps

- Turbine Trip, Turbine Trip with Loss of Offsite Power, and Loss of AC Power

- LOCA Testing

- 3/8" SBLOCA

- 1" LOCA

○ 2" LOCA

- 3.5" LOCA

○ 4.5" LOCA

- Low Level Critical Heat Flux Testing

- ECCS Characterization Tests (various)

- Loss of Feedwater with LOOP

Data sets from these transient tests already conducted are proprietary but could be available to INL pending a BWXT legal review and, potentially, a non-disclosure agreement. 


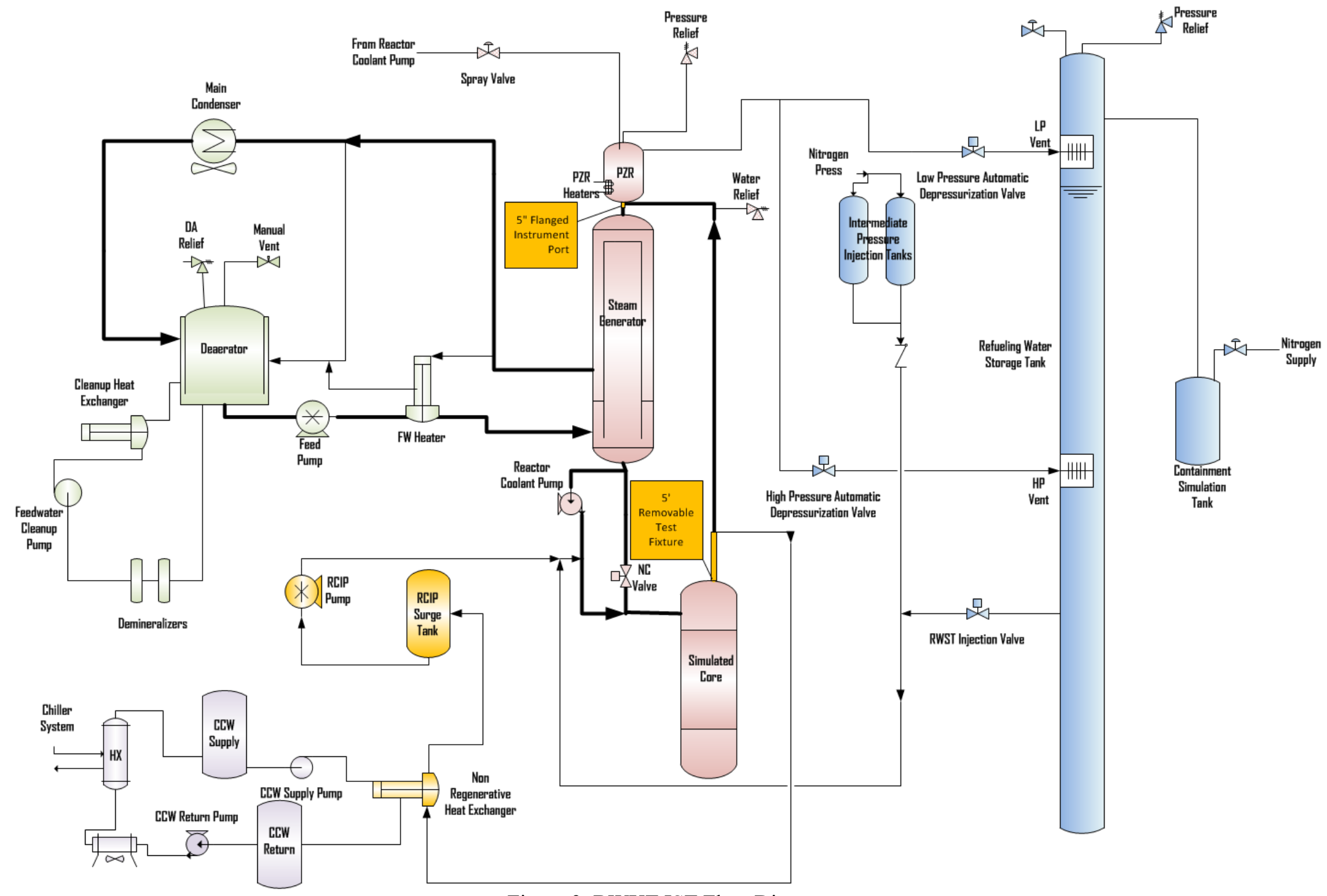

Figure 3. BWXT IST Flow Diagram 


\section{Conclusions and Next Steps}

Three facilities have been evaluated for their ability to provide real-time system response data to DETAIL. Ideally, the data from these facilities should emulate the dynamic response of a nuclear reactor system to the demands of an integrated nuclear-renewable energy system used to produce both electricity and other non-electric commodities.

The BWXT IST requires capital investment from INL/DOE to be re-started and to put the necessary staff in place, as it has been shut down for several years. The facility meets the requirements for this evaluation and is similar in scope to the SMR currently being evaluated for IES demonstration.

The NuScale NIST-1 is fully functional and currently supporting NRC design certification for the NPM. As such, there are constraints on when real-time testing for TEDS could be scheduled. The NIST-1 facility most closely matches INL's electrically-heated testing goals as it would allow preliminary demonstration prior to implementation of IES concepts in the JUMP facility.

The Framatome PKL III is available for testing but requires some programming work by Framatome in order to emulate power operations of a reactor (there is currently no reactivity feedback control program in place for the installed heater elements, but this programming could be implemented if deemed necessary). 